\title{
Особенности формирования наночастиц $\mathrm{Al}$ в полимерных суспензиях на основе Na-КМЦ из микрочастиц Al
}

\author{
Антонова Н. М. ${ }^{1,}$, Бабичев А.П. ${ }^{2}$ \\ ${ }^{1}$ Каменский институт (филиал) Южно - Российского государственного технического университета (НПИ), \\ г. Каменск \\ ${ }^{2}$ Донской государственный технический университет, г. Ростов-на-Дону \\ ${ }^{\dagger}$ melnik1@ rambler.ru

\section{The characteristics of $\mathrm{Al}$ nanoparticle formation from Al microparticles in polymer suspensions based on $\mathrm{Na}-\mathrm{CMC}$} \\ N.M. Antonova, A.P. Babichev \\ Kamensky Institute of the South - Russian State Technical University, Kamensk \\ Don State Technical University, Rostov-on-Don
}

Рассчитаны величины энергии активации вязкого течения суспензий с микрочастицами $\mathrm{Al}$ размерами менее 40 и 10 мкм в водных растворах полимера натрий - карбоксиметилцеллюлозы. При уменьшении размеров частиц $\mathrm{Al}$ энергия активации уменьшается, водородные связи разрушаются, что подтверждено методами ИК - спектроскопии. Показано, что Al -содержащие наночастицы, сформированные в суспензиях, имеют морфологию трубчатых структур размерами до 150 нм и агломерированы в объемные структуры размером до 1,5 мкм.

Ключевые слова: наночастицы алюминия, суспензия, натрийкарбоксиметилцеллюлоза, энергия активации.

\section{1. Введение}

Материалы, содержащие наночастицы, находят применение во многих областях науки и техники. Модификация защитных покрытий малыми добавками наночастиц приводит к улучшению их физико-механических, барьерных, трибологических свойств. Изучен синтез гибридных наноразмерных материалов на основе стабилизирующих полимерных матриц при взаимодействии водных растворов полисахаридов с ионами металлов [1]. Исследований, касающихся возможности получения металлосодержащих наноразмерных частиц (НРЧ) в водных растворах полимеров, при введении в них непосредственно микрочастиц металлов, крайне мало [2]. Задача получения наночастиц при использовании мелких фракций металлических порошков простыми и дешевыми методами является актуальной.

Ранее нами были получены $\mathrm{Al}$ - содержащие НРЧ [3], изготовленные из суспензий водного раствора полимера натрий - карбоксиметилцеллюлозы (Na-КМЦ) с частицами порошка алюминия марки АСД-1, микродобавками порошка Со, и изучены особенности их стро-
The values of activation energy for viscous flow of suspensions with microparticles of $\mathrm{Al}$ having sizes less than 40 and $10 \mu \mathrm{m}$ in water solutions of $\mathrm{Na}$-carboxymethylcel cellulose polymer are calculated. With a decrease of the Al particle sizes the activation energy decreases, the hydrogen bonds are broken that is confirmed by the methods of infrared spectroscopy. It is shown that $\mathrm{Al}$ containing nanoparticles formed in suspensions have a morphology of tubular structures with sizes about $150 \mathrm{~nm}$ and are agglomerated to bulk structures with sizes up to $1.5 \mu \mathrm{m}$.

Key words: aluminum nanoparticles, suspension, natrium-carboxymethylcel cellulose, activation energy.

ения. Порошок Со был выбран в качестве катализатора на основании литературных данных [2]. Методами РФА, РЭМ и ИК - спектроскопии было установлено, что в НРЧ присутствует Al, а полимерная матрица Na-КМЦ coхраняется без кардинальных трансформаций [3]. Полученные композиты содержали как вновь образованные наноструктуры, так и сравнительно крупные микрочастицы исходного порошка Al. Настоящая работа является продолжением проведенных исследований. В ходе предварительных исследований было выявлено, что на однородность полученных НРЧ в значительной мере влияют размер частиц $\mathrm{Al}$, интенсивность межмолекулярных взаимодействий, характеристикой которых является величина энергии активации вязкого течения [4], подвижность структурных элементов в процессе вязкого течения, и как следствие, реологические свойства водных растворов Na-КМЦ. В настоящей работе проведено исследование структурообразования Al-содержащих НРЧ, полученных при взаимодействии полимерной суспензии Na-КМЦ с алюминиевыми порошками АСД-1 (размер частиц $\mathrm{d}<40$ мкм), АСД-6 (d<10 мкм). 
Целью работы являлось изучение влияния реологических свойств суспензий на формирование металлорганических НРЧ, обладающих сравнительно однородной структурой и не содержащих исходных микрочастиц алюминия.

\section{2. Материалы и методики исследований}

Исследовали гелеобразный 2,9 \% водный раствор очищенного порошка $\mathrm{Na}$ - КМЦ без добавок и суспензии, полученные смешиванием раствора $\mathrm{Na}$ - КМЦ с частицами металлических порошков АСД-1, АСД-6. Рассев металлических порошков производился на электростатическом анализаторе ЭЛСА-2. Соотношения компонентов (табл. 1) и температурный режим были выбраны на основании данных, полученных в ходе предварительных исследований. НРЧ получали высушиванием суспензий на фторопластовых подложках при температуре $(70 \pm 1)^{\circ} \mathrm{C}$ до постоянного веса.

Реологические характеристики суспензий получали на ротационном вискозиметре Брукфильда DV-II+PRO. Измерения проводили при температурах 298,0 К, 313,0 К и 333,0 К в диапазоне вязкости 6,219 ...1,212 Пахс.

Инфракрасные спектры (ИК-спектры) регистрировали на спектрофотометре Varian Excalibur 3100 FT-IR в интервале 600-4000 $\mathrm{cm}^{-1}$ методом нарушенного полного внутреннего отражения.

Морфологию и элементный состав исходных и полученных в эксперименте порошков с НРЧ, исследовали с помощью электронно-сканирующих микроскопов Quanta 200 на оборудовании ЦКП «Нанотехнологии ЮРГТУ (НПИ)» и Hitachi S - 5500 (институт химии ДВО $\mathrm{PAH})$.

\section{3.Результаты и их обсуждение}

Полученные ранее НРЧ [3] изготавливались с исполь-

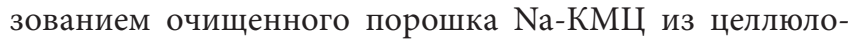
зы Байкальского ЦБК, порошка алюминия АСД - 1 и микродобавок порошка кобальта. Однако, у «мокрого» способа формирования НРЧ в присутствии кобальта имеется существенный недостаток: микродобавки Сo, выступающего в роли катализатора, затруднительно распределить в суспензии равномерно. Синтез струк-

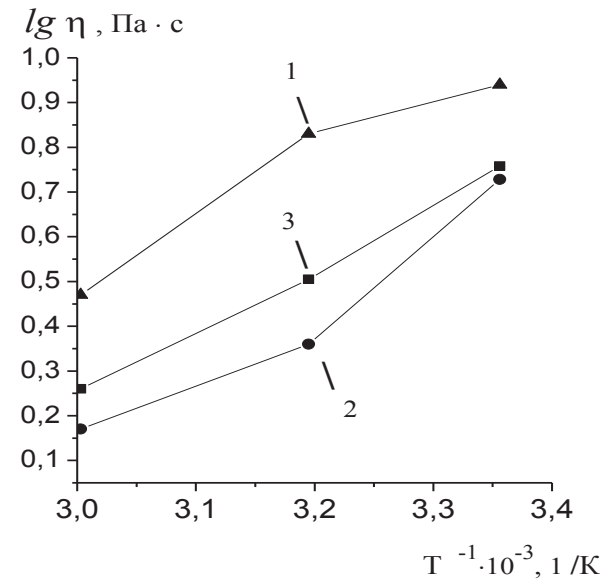

Рис. 1. Изменение вязкости суспензий в режиме нагревания ( $\omega=30$ об/мин). турно - однородных наночастиц в таких суспензиях невозможен. Наряду с этим известно, что элементный состав полимерного порошка Na-КМЦ в значительной мере обусловлен исходным природным древесным сырьем, а порошок Na-КМЦ нередко содержит малые количества металлов, в том числе и кобальт. При анализе элементного состава очищенного порошка Na-КМЦ, изготовленного из целлюлозы Байкальского ЦБК, было выявлено, что в образце превалируют углерод, кислород, натрий, хлор и отсутствует кобальт. Поэтому для дальнейших исследований использовался порошок $\mathrm{Na}$ КМЦ, изготовленный из целлюлозы Сяйского ЦБК, имеющий близкий к Байкальской целлюлозе элементный состав, но содержащий дополнительно Со в количестве 0,55 мас. \%. Внешнее добавление порошка кобальта при этом не производили.

Для установления интенсивности межмолекулярного взаимодействия в композициях определялись значения кажущейся энергии активации вязкого течения. Зависимость эффективной вязкости в области обратных температур $T^{-1}$ для диапазона $\mathrm{T}=298,0 \div 333,0$ К в полулогарифмической шкале координат приведена на рис. 1. Полученные зависимости $\lg \eta$ от $1 / T$ близки к линейным, поэтому для систем на основе водных растворов Na-КМЦ рассчитаны кажущиеся энергии активации вязкого течения [4] в указанном диапазоне температур по уравнению:

$$
\eta=A \cdot e^{\Delta E / R T},
$$

где $\Delta E$ - кажущаяся энергия активации вязкого течения, $R$ - универсальная газовая постоянная, $T$ - абсолютная температура, $A$ - константа. Значения энергии активации представлены в табл. 2.

Из таблицы видно, что в суспензиях с наполнителем АСД-1 значение $\Delta E$ значительно больше, а в суспензиях с АСД-6 меньше, чем в водном растворе $\mathrm{Na}-$ КМЦ.

При анализе ИК - спектров основное внимание уделено анализу интенсивностей полос в области валентных колебаний ОН - групп (3200 - $\left.3800 \mathrm{~cm}^{-1}\right)$. Из рис. 2-3 видно, что в области $3400-3800 \mathrm{~cm}^{-1}$ ИК - спектры практически идентичны. В спектрах порошка Na-КМЦ и порошков с НРЧ присутствует полоса поглощения в области 3350-3200 см$^{-1}$. Интенсивность этой полосы для порошка с НРЧ из состава $2\left(3290 \mathrm{~cm}^{-1}\right)$ значительно

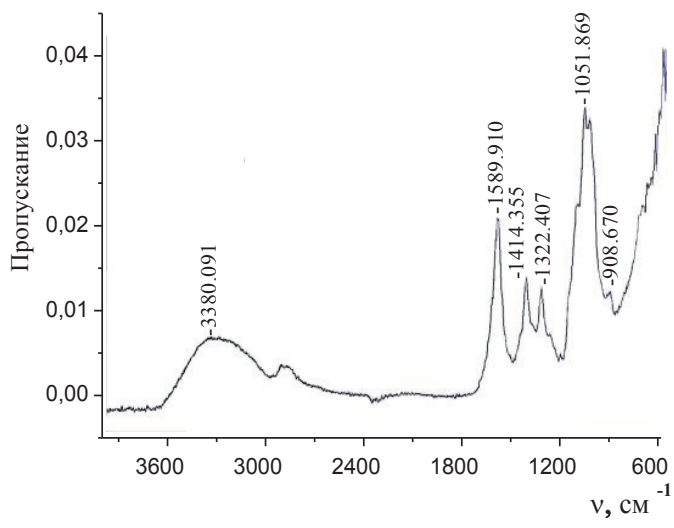

Рис. 2. ИК-спектр порошка Na-КМЦ. 


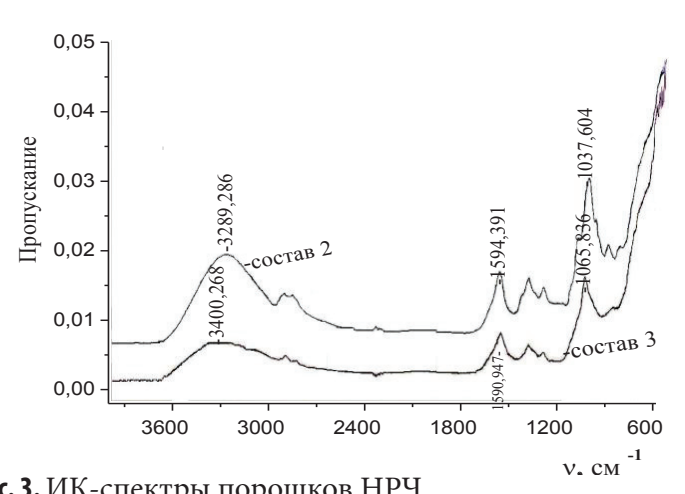

Рис. 3. ИК-спектры порошков НРЧ.

выше, а для состава 3 - ниже, чем у исходного порошка $\mathrm{Na}-$ КМЦ. Полоса поглощения в области $1590 \mathrm{~cm}^{-1}$, присутствующая во всех спектрах, соответствует группе $\mathrm{C}=\mathrm{O}$ при внутримолекулярной водородной связи, на что указывает широкая полоса поглощения в области 3350$3200 \mathrm{~cm}^{-1}$. Интенсивность полосы $1590 \mathrm{~cm}^{-1}$ по сравнению со спектром Na-КМЦ в обоих случаях уменьшается, что свидетельствует о нарушении внутримолекулярных водородных связей непосредственно между макромолекулами полимера в суспензиях с металлическими наполнителями [5]. Эти полосы характеризуют участие гидроксильных групп макромолекул во взаимодействии с оксидными оболочками частиц Al. Сопоставление из-

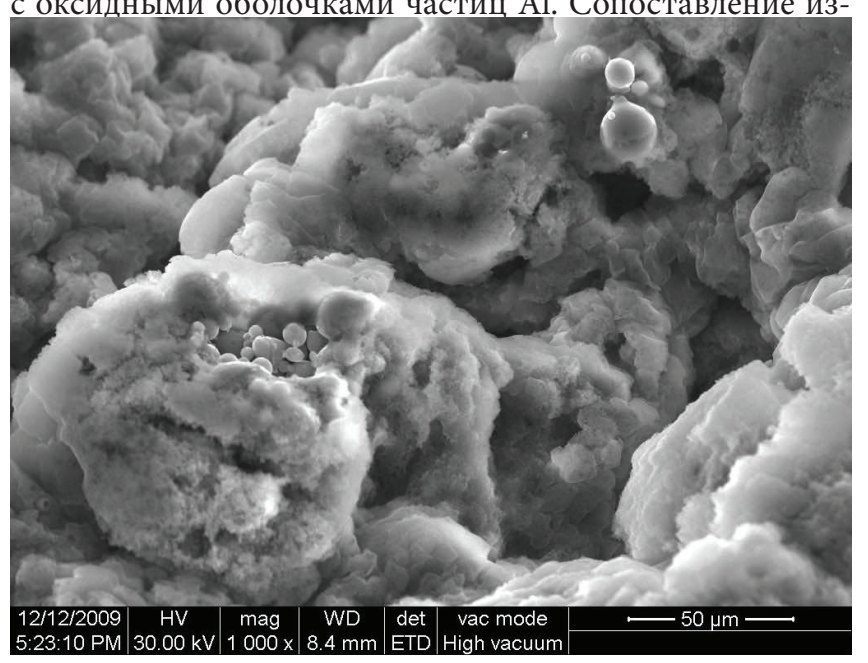

a)

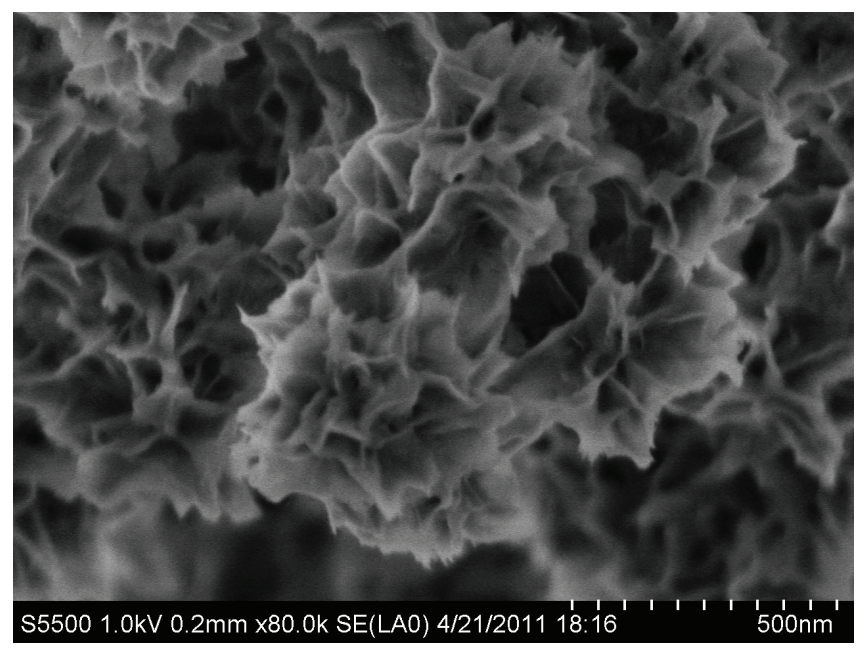

B) менений величин $\Delta \mathrm{E}$ и данных ИК - спектроскопии позволяет сделать вывод, что в суспензии с крупной фракцией порошка алюминия (менее 40 мкм) превалируют водородные связи, участвующие во взаимодействии с оксидными оболочками алюминия и макромолекул полимера между собой. В НРЧ - порошке, изготовленном из суспензии с более мелкой фракцией алюминия (менее 10 мкм) таких связей значительно меньше.

Механизм образования НРЧ в суспензии может быть следующим. Растворы Na-КМЦ представляют собой ассоциаты стержнеобразных макромолекул со свернутыми в клубки макромолекулами. Рост температуры приводит к разворачиванию клубковых макромолекул и увеличению активных звеньев, доступных для возможных связей с соседними макромолекулами и растворителем водой. Микрочастицы $\mathrm{Al}$, взаимодействуя с Na-КМЦ, изменяют молекулярную подвижность цепей и увеличивают структурированность раствора. Специфика реологического процесса обусловлена химическим строением макромолекул полимера, определяющим поведение полианионных макромолекул Na-КМЦ в водных системах и их взаимное отталкивание [6]. Жесткоцепные по своей конформационной структуре макромолекулы $\mathrm{Na}$ КМЦ, отталкиваясь, образуют в суспензии полимерную матрицу с распределенными микрочастицами алюминия. В результате образуются водородные связи между

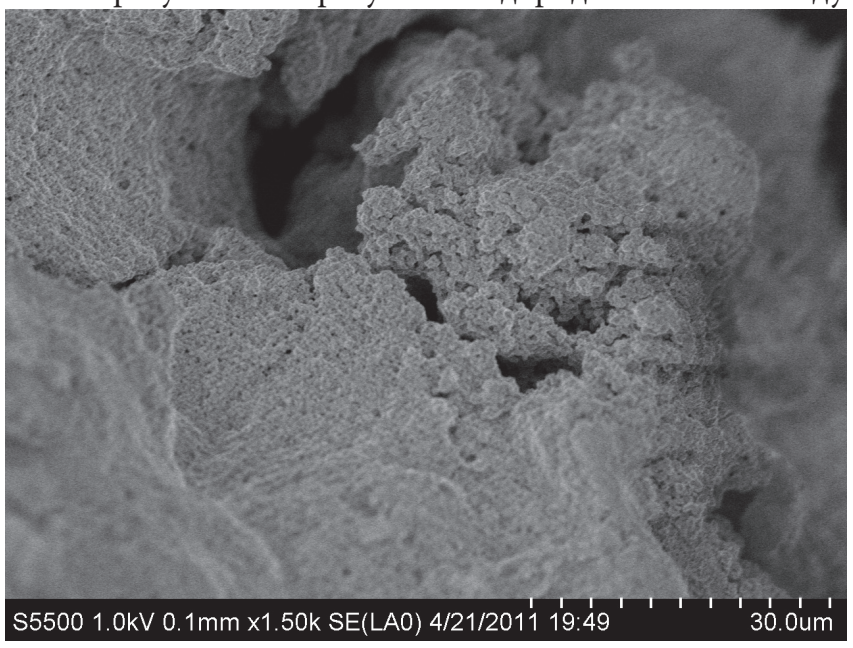

б)

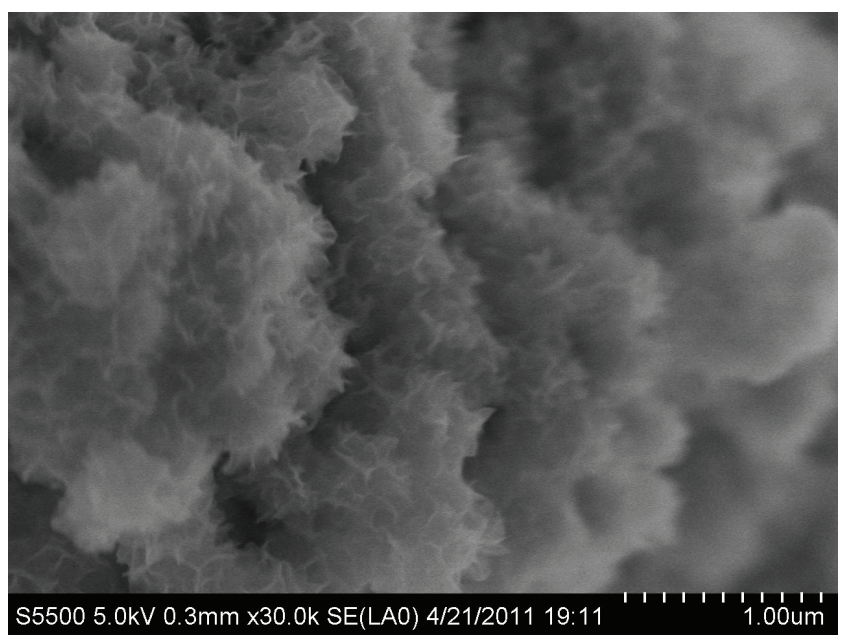

г)

Рис. 4. Микрофотографии НРЧ: а) -из состава 2; 6, в, г) -из состава 3. 
активными гидроксильными группами макромолекул и гидроксокомплексами алюминия. В работе [3] было показано, что наряду с возникновением дополнительных водородных связей имеет место проникновение $\mathrm{H}_{2} \mathrm{O}$ непосредственно к поверхности активного металла. Этому способствуют дефекты оксидной оболочки микрочастиц алюминия. На таких участках происходит своеобразное «вытравливание» частицы. РЭМ-анализ мелкой фракции порошка алюминия (менее 10 мкм) показал наличие частиц, размеры которых менее 0,1 мкм. Диффузионные затруднения в этом случае минимальны, и доминирует химико-механический эффект: разрыв оболочки приводит к проникновению $\mathrm{H}_{2} \mathrm{O}$ непосредственно к поверхности активного металла и возникновению НРЧ, образованных алюминием, экранированным натрий - карбоксиметилцеллозной оболочкой [3]. В суспензии с микрочастицами алюминия размерами менее 40 мкм превалируют взаимодействия посредством водородных связей. Таким образом, полученные структуры содержат исходные сравнительно крупные частицы $\mathrm{Al}$ (рис. 4 a) при применении крупной фракции (до 40 мкм) и практически не содержат исходных микрочастиц $\mathrm{Al}$ (рис. 4 б) при применении мелкой фракции (до 10 мкм) порошка алюминия. Детальное рассмотрение изображений структур, полученных из фракции размерами менее 10 мкм (рис. 4 в) показывает, что полученные наноразмерные частицы состоят из трубчатых структур. Базальтовое (внутри слоев) пространство трубок составляет $50 \div 150$ нм, толщина стенки трубки $-3 \div 10$ нм. Трубки собраны в обособленные рыхлые клубки размерами 0,3 мкм, а клубки, в свою очередь, в объемные агломераты до 1,5 мкм (рис. 4 г).

\section{4. Выводы}

1. Показана возможность получения наноразмерных алюминий - содержащих структур путем введения микрочастиц $\mathrm{Al}$ в водный раствор Na-КМЦ. Агломераты полученных частиц достигают величины 1,5 мкм и состоят из трубчатых структур размерами до $150 \div 160$ нм.

2. Установлено, что значение энергии активации вязкого течения суспензий с микрочастицами алюминия размерами до 40 мкм возрастает за счет водородных связей, доступных для взаимодействия в $\mathrm{OH}$ - группах водного раствора полимера. При уменьшении размеров частиц $\mathrm{Al}$ до 10 мкм энергия активации уменьшается, водородные связи частично разрушаются, что подтверждено методами ИК - спектроскопии.

\section{Литература}

1. Помогайло А.Д. Металлополимерные нанокомпозиты с контролируемой молекулярной архитектурой. Рос. хим.журн. 2002, T. XLVI, № 5, С. 64-73.

2. Помогайло А.Д., Розенберг А.С., Уфлянд И.Е. Наночастицы металлов в полимерах. М.: Химия, 2000, 672 c.

3. Антонова Н.М., Бабичев А.П., Дорофеев В.Ю. Особенности формирования структуры Alсодержащих нанокомпозитов при взаимодействии порошка АСД-6 с полимерной суспензией. Коррозия: материалы, защита. 2011, № 9, С. 40-44.

4. Геллер Б.Э., Геллер А.А., Чиртулов В.Г. Практическое руководство по физикохимии волокнообразующих полимеров. М.: Химия, 1996, 432 с.

5. Белами Л. Инфракрасные спектры сложных молекул: Пер. с англ. М.: Изд-во иностр. лит., 1963, 590 с.

6. Петропавловский Г.А. Гидрофильные и частично замещенные эфиры целлюлозы и их модификация путем химического сшивания целлюлозы. Л.: Наука, 1988, 298 c. 